\title{
Reflexiones sobre la vida y muerte digna
}

\section{José Luis Sandoval-Gutiérrez}

Instituto Nacional de Enfermedades Respiratorias, Subdirección de Servicios Auxiliares de Diagnóstico y Paramédicos, Ciudad de México, México

Si no existiera la muerte, la inventaría para vivir intensamente. ANóNIMO Morir no es una novedad, pero tampoco es nuevo vivir

ESENIN

En un estudio reciente se reporta que menos de $20 \%$ de los médicos pediatras tiene una actitud positiva hacia la muerte. ${ }^{1}$ La Academia Nacional de Medicina de México ha presentado una postura en relación con las decisiones sobre el final de la vida, ${ }^{2}$ lo que motiva a formular una reflexión sobre el tema.

En un curso de tanatología en un hospital privado, una participante-paciente oncológica comentaba "acepto la muerte, pero no acepto el dolor". Esas sabias palabras de una mujer en la tercera década de la vida, quien no concluyó el curso debido a que semanas después falleció y su hermana lo terminó en su honor, han quedado en mi memoria en los últimos años. Ella, una mujer con estudios universitarios y posgrado, gerente de un banco, quien luchó contra un cáncer de mama con metástasis, comentaba en la sesión académica ante personal de salud que cursaba el diplomado, que sus médicos no le querían aumentar la dosis de morfina por el riesgo de hacerse adicta; en un tono simpático nos aseguraba que fallecería antes de que lograse desarrollar dicha adicción.

Por formación profesional, los médicos hemos considerado a la muerte como la gran enemiga a vencer y que debemos utilizar todos los medios físicos y tecnológicos para evitarla en nuestros pacientes. Las innovaciones en terapia intensiva, el entrenamiento en esta especialidad por médicos y enfermeras, las exigencias de pacientes y familiares de dar todo lo que sea posible al enfermo no importando la edad o la situación de avance de enfermedad, han provocado que los nuevos educandos no tengan una reflexión adecuada sobre la inevitabilidad de esta condición humana.

Recuerdo a un paciente de 93 años que estaba con ventilación mecánica en un hospital público debido a una neumonía, quien además tenía falla renal y hepática. Su hija, médico, comentaba: "mi papá, aunque lo vea grande, ama la vida, así que por favor háganle todo".

Los retos en los siguientes años son educar y promover el concepto de vida y muerte digna. Nadie debe tener dolor si existen las condiciones y medicamentos para evitarlo; nadie debe tener sufrimiento si hay lugares para manejarlo. No continuar con un tratamiento avanzado que no ha dado resultado no es un acto de cobardía ni negligencia, por el contrario, es una actitud inteligente y acertada ante una inminente realidad.

\section{González Martínez comenta: ${ }^{3}$}

Una medicina competente solo en lo científico no puede ayudar al paciente a enfrentar su pérdida de salud o encontrar el significado del sufrimiento; además de la capacidad científica, los médicos necesitan escuchar las narraciones de sus pacientes, comprender y glorificar sus significados y actuar en beneficio de ellos. Las expresiones verbales y no verbales que surgen en el escenario del encuentro humano y técnico entre un médico y un paciente durante la consulta médica, lo ponen en el camino correcto para establecer un diagnóstico preciso y un tratamiento efectivo, de ahí que para el ejercicio de una medicina humana, técnica y socialmente eficaz y en función de los progresos tecnológicos, parece cada vez más indispensable formar sólidamente al médico en las vertientes antropológicas y éticas de sus profesión, así como entrenarlo para que domine habilidades y destrezas. Ninguna tecnología, por útil que sea, puede remplazar a un médico inteligente y hábil que emplea su capacidad intelectual y sus sentidos para comunicarse con su paciente de un modo
Fecha de recepción: 18-03-2019

Fecha de aceptación: 16-05-2019

DOI: 10.24875/GMM.19005170
Gac Med Mex. 2019;155:330-331

Disponible en PubMed www.gacetamedicademexico.com 
efectivo durante la consulta médica, obteniendo de la anamnesis y el examen físico datos para elaborar un diagnóstico certero y, en consecuencia, prescribir un tratamiento eficaz al enfermo; la mayor parte de la terapéutica es a través del médico.

\section{Como Gutiérrez Samperio dice: ${ }^{4}$}

El concepto de medicina paliativa es, con frecuencia erróneo: se considera que indicarla y utilizarla equivale a "no hacer nada", lo que está absolutamente alejado de la realidad. El fin es suprimir el dolor y otros síntomas molestos, evitar (dentro de lo posible) el sufrimiento y, de esta manera, mejorar la calidad de vida, con el fin de que el enfermo tenga la voluntad de preservar una vida que se pueda considerar digna.
Es importante que el médico de este milenio reflexione ampliamente sobre los conceptos de vida, muerte y dignidad, para beneficio de los pacientes y de su propia labor profesional.

\section{Bibliografía}

1. Sánchez-Sánchez LM, López-Córdova ED, Siller-Gómez P. Actitud del personal médico de un servicio de pediatría ante la muerte de los pacientes. Gac Med Mex. 2018;154(2):152-160.

2. Mansilla-Olivares A, López-Bárcena J, Plancarte-Sánchez R, Valenzuela-Gómez-Gallardo F, Rojo J, Meneses-González F, et al. Postura de la Academia Nacional de Medicina de México en relación con las decisiones sobre el final de la vida. Gac Med Mex. 2018;154(6):732-736.

3. González-Martínez JF, León-Paoletti Al. El reto de ser médico. Segunda edición. Ediciones y Servicios Editoriales: 2017.

4. Gutiérrez-Samperio C. Medicina paliativa. Ciruj Gen 2017;39(4):251-256. 